\title{
An Overview of China's Agricultural Non-point Source Issues and the Development of Related Research
}

\author{
Shen $Z^{*}$, Baia J, Liaoa $Q$ and Chena $L$
}

State Key Laboratory of Water Environment Simulation, School of Environment, Beijing Normal University, Beijing 100875, PR China

*Corresponding author: Shen Z, State Key Laboratory of Water Environment Simulation, School of Environment, Beijing Normal University, Beijing 100875, PR China, Tel: +86 10 58800398; E-mail: zyshen@bnu.edu.cn

Rec date: Jul 08, 2014; Acc date: Aug 06, 2014; Pub date: Aug 16, 2014

Copyright: (c) 2014 Shen Z, et al. This is an open-access article distributed under the terms of the Creative Commons Attribution License, which permits unrestricted use, distribution, and reproduction in any medium, provided the original author and source are credited.

\begin{abstract}
Non-point Source (NPS) pollution has become an important concern in the protection of the aquatic environment and has received increased attention in recent years. In China, NPS pollution control is one of most important issues that need to be addressed to protect the aquatic environment in the next few decades. This paper reviewed and summarized three aspects of current agricultural NPS pollution studies in China: mechanisms, simulation models, and control technologies. This review outlines some shortcomings of previous research and the opportunities for future research. The results of this study indicated that the present research on NPS pollution mechanisms is not adequate. The lack of a database system, the uncertainty of models, and other issues have an effect on model applications. Control technology is still the only technique used for minimizing NPS pollution. For future studies, understanding and absorbing foreign NPS models, modifying related processes, and using related key parameters that are modified using Chinese characteristics are necessary for NPS pollution modeling in China. Furthermore, research on NPS mechanisms and system control technologies at a watershed scale will also be a key issue.
\end{abstract}

Keywords: China; Non-point source; Overview; Mechanism; Simulation models; Control technology

\section{Introduction}

In conjunction with agricultural development and the increasing amount of chemical fertilizers and pesticides used in China, there is a growing body of evidence that non-point source (NPS) pollution, especially agricultural NPS pollution, is a particularly serious problem in the management of water quality in China [1]. Investigation of Eutrophication in the Dianchi watershed suggests that the Total Nitrogen (TN) generated by NPS pollution comprises $44.5 \%$ of the total pollution load, whereas the Total Phosphorus (TP) comprises 26.7\% [2]. Similarly, survey results in the Taihu lake watershed show that the TN and TP loads generated by NPS pollution were $59 \%$ and $30 \%$, respectively [3]. It is apparent that NPS pollution has become a primary threat to watershed health in China.

Research about agricultural NPS pollution in China began in the early 1980s with research about the relationship between land use and NPS pollution and the statistical calculation of the pollution load at certain severely polluted sites, such as Dianchi Lake and the Yellow River Watershed. Chinese scholars have also conducted in-depth studies about pollution mechanisms and their influencing factors since the 1990s [4]. Furthermore, studies modeling NPS pollution have been a core topic because of their quantitative descriptions and more accurate simulations of NPS loads and distribution. However, this research has not generated a systematic methodology.

This paper reviews and summarizes three aspects of the state-ofthe-art methods on agricultural NPS pollution in China: mechanisms, simulation models, and control technologies and management system of agricultural NPS pollution in China. This paper also describes some of the merits and shortcomings of previous research and predicts the direction of future research.

\section{Development of NPS Mechanisms in China}

The migration and transformation mechanisms of agricultural NPS pollution are the basis of quantitative modeling and control studies. Agricultural NPS is a continuous dynamic process that is primarily driven by the following processes: rainfall runoff, soil erosion, solute dissolution from surfaces, and solute leakage in soil [5], which are all related processes.

\section{Rainfall runoff}

Research about rainfall runoff is mostly based on hydrology and focuses on runoff yield characteristics and the runoff concentration process. The Soil Conservation Service (SCS) Curve Number (CN) equation is widely used in NPS studies by Chinese scholars when considering factors that influence the spatial differences of an underlying surface (such as land use, soil permeability, and rainfall) [6,7]. Li and Shen [8] presented storage, saturation excess, and integrated runoff yield theories of regional agricultural NPS runoff yield calculations based on China's actual situation. In terms of runoff concentration calculations, the unit hydrograph method (especially the Nash unit hydrograph method) is one of the most extensively used methods in China. However, this method has some obvious deficiencies, such as unreasonable physical concepts (assuming that all net rainfall is concentrated in the upper reaches) and smaller peak values in the northern the arid region.

\section{Soil erosion}

Soil erosion studies can be classified into three levels: slope surface, small watershed and river basin in accordance with different spatial scale [9]. Each erosion class has a specific sediment yield mechanism.

Studies of slope erosion in China began in the 1970s, concentrating on statistical methods. Chinese scholars used the Universal Soil Loss 
Equation (USLE) and its revised RUSLE model to calculate various factors and soil loss slopes based on measurement data. In recent years, in-depth research has evaluated the physical erosion process. $\mathrm{Wu}$ et al. [10] researched the internal hydrodynamic mechanism of slope erosion from rainfall, defined the relationship between overland flow and slope particles, and obtained the critical rainfall erosion intensity of erosion for different kinds of particles. Wu and Wang [11] concluded that the relationship between soil erosion and its geographical factors. $94.5 \%$ of soil erosion occurred in areas less than $500 \mathrm{~m}$ and $85.3 \%$ presented on the areas between $15^{\circ}-35^{\circ}$.

Studies of the erosion mechanisms in small watersheds consider channel erosion and sand movement on the basis of slope surface erosion. Liu et al. [12] developed a mathematical model for calculating the flow network and sand movement of a land-unit, which they defined as a piece of land with homogeneous geographic characteristics. Liu et al. [9] moved forward to simplify the ridge, slope, and channel models, by replacing the climate factors with meteorological data and by proposing a typical soil erosion model that is feasible for a small watershed. This model produced reasonable simulation results in many northwestern watersheds. At present, small watersheds have been used extensively for the study of the Karst and Loess Plateau landscape in China [13,14].

River basin soil erosion studies usually divide the study region into several basic units; therefore, the methods for small watershed described above can be used to calculate a regional yield. At present, there are two primary methods that are used to research surface runoff and soil erosion at a large regional scale: standard runoff plots and artificial simulations of rainfall. The former method was used by Liu et al. [15] to research the relationship between rainfall intensity, the antecedent soil moisture content, and the vegetation cover status, which were the main factors that affected surface runoff. The latter method was used by Gan et al. [16] to study the effects of grassland vegetation on the progress of running off and soil erosion.

\section{Solute dissolution from surface}

Research on surface solute dissolution in China started relatively late compared with developed countries. These studies began in the mid-1980s and mainly focused on nitrogen and phosphorus losses into coastal areas and on the Loess plateau. There are several studies about the mechanisms of nitrogen and phosphorus surface runoff from farmland and its effects in China since the mid-1990s. The main factor that affects nitrogen loss is the weather. Surface runoff caused by heavy rain is a primary route of nitrogen loss. Therefore, the types, intensity, and timing of precipitation are key factors affecting nitrogen loss [17]. Furthermore, there are many other factors that affect nitrogen loss, such as soil characteristics, fertilizer type, land use, and field management, among which the fertilization mode is a key factor [18].

Phosphorus loss is mainly determined based on adsorption. There are two routes for phosphorus pollution migration and transport in an agricultural watershed: transport in surface runoff and in subsurface flows. Recent studies in China have shown that soil phosphorus losses have a significant positive correlation with precipitation and are influenced by the slope, slope length, land use, and vegetation coverage [19]. Furthermore, the soil type, cultivation methods, and fertilizer types also have an impact on the mechanisms of phosphorus loss. For example, ploughing, which is a traditional cultivation method in China, causes a high migration rate of phosphorus. Meanwhile, the more phosphorus fertilizer used, the greater is the possibility of phosphorus loss. Research shows that different land uses have an influence on the transformation of phosphorus: grasslands and woodlands have more dissolved phosphorus, whereas agricultural land has more particulate phosphorus.

In addition to primary pollutants such as nitrogen and phosphorus, the transformation and transport of pesticides and other toxic pollutants are also drawing increased attention. The transformation and transport of pesticides are greatly affected by the pesticide application method. At present, foliage sprays and applications directly to the field are the two primary pesticide application methods. China has been the world's largest consumer of pesticides for more than 10 years [4]. The latest research focus has changed from the fate and transport simulation into the source tracking and management measures [20-22]. However, Chinese pesticide research is mainly focused on determining the extent of pesticide residues in soil and water. Along with the development of research, some scholars have studied on the transformation of pesticides in small watersheds.

\section{Solute leakage in soil}

The transport of dissolved NPS pollutants into the lower layer of the soil is an extremely complex process that influenced by soil characteristics, crops, microorganisms, and many other factors. Transport mechanisms and the distribution of solutes are important issues in the field of soil solute transport theory studies. In particular, studies about nitrogen seepage at a farmland field scale are the most popular topics. The research about NPS pollutants in soil mainly focuses on experimental simulation and theoretical research. Experimental simulation includes soil adsorption, total nitrogen and phosphorus leaching, transport and transformation, and their influencing factors. These factors are composed of various aspects, such as precipitation, irrigation mode, soil texture, cultivation method, and fertilizer type $[23,24]$. Theoretical study involves mathematical simulation based on an experiment.

\section{Development of NPS Pollution Modeling in China}

\section{Applications and improvements of exotic NPS pollution modeling}

China has a relatively short history of NPS pollution modeling research compared with countries in North America, where mathematical models have been used since the 1960s to assess NPS pollution loads. These models can be divided into two categories, empirical or statistical models and physically-based or process-based models [25]. Empirical models use monitoring data in typical experimental plots to establish empirical relationships between hydrological parameters, whereas physically-based models combine hydrological models, soil erosion models, and pollutant migration models to form a relatively complete model system. The majority of work that has been conducted involves the application of sophisticated models developed by western countries in some typical areas, with parameter amendments based on the specific local conditions of China. Shen et al. [26] wrote a paper focused on this topic, so only a brief introduction is included here.

Empirical modeling: Statistical methods, an export coefficient model (ECM), an improved export coefficient model (IECM), and a Hydrograph Separation Method are the public domain of the empirical models that have been used extensively in China (Table 1). 


\begin{tabular}{|l|l|l|}
\hline Method & Application examples & Study location \\
\hline $\begin{array}{l}\text { 1. Statistical methods } \\
\text { 2. ECM }\end{array}$ & $\begin{array}{l}\text { A linear correlation between the unit load of TP, TN and sediment was } \\
\text { established by measuring single event data. }\end{array}$ & $\begin{array}{l}\text { Heihe, Hanjing } \\
\text { Watersheds }\end{array}$ \\
\hline $\begin{array}{l}\text { Relation between nitrogen export and land use was analyzed by using } \\
\text { hydrological modeling method. }\end{array}$ & $\begin{array}{l}\text { Hujiashan Watershed of Danjiangkou } \\
\text { Reservoir }\end{array}$ \\
[ECM & $\begin{array}{l}\text { Precipitation and terrain impact factors were introduced to improve the } \\
\text { [2CM. }\end{array}$ & Upper Reach of the Yangze River \\
\hline $\begin{array}{l}\text { 4. Hydrograph Separation } \\
\text { Method }\end{array}$ & Divide pollution load into point source and NPS. & Weihe River Watershed \\
\hline
\end{tabular}

Table 1: Empirical modeling methods commonly used in China and their applications

\begin{tabular}{|c|c|c|c|}
\hline Method & Application examples & Study location & $\begin{array}{l}\text { Sour } \\
\text { ce }\end{array}$ \\
\hline \multirow[t]{8}{*}{ 1. SWAT } & \multicolumn{3}{|l|}{ 1) Hydrological predictions: } \\
\hline & $\begin{array}{l}\text { Simulation about the daily runoff of the } \\
\text { montane mixed replenishment of ice } \\
\text { and snowmelt river. }\end{array}$ & $\begin{array}{l}\text { Manasi } \\
\text { Watershed in } \\
\text { Xinjiang } \\
\text { Province }\end{array}$ & {$[31]$} \\
\hline & \multicolumn{2}{|l|}{ 2) Water Quality Studies: } & \\
\hline & $\begin{array}{l}\text { Application for NPS pollution load } \\
\text { prediction based on calibration and } \\
\text { validation. }\end{array}$ & $\begin{array}{l}\text { Daning River } \\
\text { Watershed in } \\
\text { Three Gorges } \\
\text { Reservoir }\end{array}$ & [32] \\
\hline & \multicolumn{2}{|l|}{ 3) Modifications and Improvements: } & \\
\hline & $\begin{array}{l}\text { The soil grain size transferring module } \\
\text { and data pre-processing module were } \\
\text { added to SWAT model for the actual } \\
\text { conditions of study area. }\end{array}$ & $\begin{array}{l}\text { Heihe River } \\
\text { Basin;Hanjiang } \\
\text { River Basin }\end{array}$ & [33] \\
\hline & \multicolumn{2}{|l|}{ 4) Parameter Uncertainty Studies: } & \\
\hline & $\begin{array}{l}\text { Five uncertainty analysis techniques } \\
\text { (including Generalized Likelihood } \\
\text { Uncertainty Estimation (GLUE), Markov } \\
\text { chain Monte Carlo (MCMC), etc.) were } \\
\text { compared for a SWAT application. }\end{array}$ & Chaohe Basin & {$[34]$} \\
\hline 2. AGNPS & $\begin{array}{l}\text { Application for runoff and nutrients } \\
\text { losses simulation and evaluation for } \\
\text { management practice effects in the } \\
\text { Southeast Asian tropics. }\end{array}$ & $\begin{array}{l}\text { Jiulong River } \\
\text { Basin }\end{array}$ & [35] \\
\hline $\begin{array}{l}\text { 3.AnnAGN } \\
\text { PS }\end{array}$ & $\begin{array}{l}\text { Application for agricultural NPS } \\
\text { pollution load simulation based on } \\
\text { parameter validation. }\end{array}$ & $\begin{array}{l}\text { Lianshui River } \\
\text { Basin }\end{array}$ & [36] \\
\hline 4. HSPF & $\begin{array}{l}\text { Simulation for runoff based on } \\
\text { parameter sensitivity analysis and } \\
\text { correction. }\end{array}$ & $\begin{array}{l}\text { Dage River } \\
\text { Watershed in } \\
\text { Miyun } \\
\text { Reservoir }\end{array}$ & [37] \\
\hline
\end{tabular}

Table 2: Agricultural NPS models extensively used in China

Physically-based and process-based modeling: The application of a distributed, physically-based method introduced from developed countries to estimate the NPS pollution in various river basins, reservoirs, and lakes has recently received a great deal of attention in China. Among various models, the SWAT model, the AGNPS model, and the HSPF model are widely used in China (Table 2).

\section{Application and improvements of native NPS pollution modeling}

Empirical modeling: In addition to learning from foreign experience, scholars in China have developed several methods based on the conditions in Chinese regions with limited monitoring data. These methods include the mean concentration method, the correlation method of water quality and quantity, the rainfall deduction method, and etc. [26].

These methods are able to obtain reasonable simulation results in their study areas. However, most of these are simple statistical methods that may not generate a precise estimate, and it is not possible to conduct an error analysis due to the lack of long sequences of rainfall runoff monitoring data.

Physically-based and process-based modeling: The IMPULSE (Integrated Model of Non-point Sources Pollution Processes) model is a typical distributed and semi-physically based NPS model that was independently developed by scholars at Tsinghua University [2]. The main physical and chemical structure of IMPULSE is similar to the widely used AGNPS model, including three sub-models of hydrology: soil erosion, sediments, and pollutant transport. However, it is more cost-effective than AGNPS, because it can simulate a large number of space combinations of Best Management Practices (BMPs) efficiently and provide an uncertainty analysis function for the model parameters. Furthermore, Zhang and Zhuang [38] developed a model system that included a watershed hydrological model and pollutantyielding model for agricultural NPS pollution prediction based on NPS the formation-characteristics and generated good prediction results in the West Liaoning Watershed.

\section{Development of NPS Control Technology and a Control Management System in China}

\section{A single technique for controlling NPS pollution}

Source control techniques: Chinese scholars have made great progress in eco-fertilizer techniques (such as soil testing, variable and prescription fertilization techniques) that can be adapted in local conditions according to the soil characteristics and crop growth conditions in China [39]. Conservation tillage has a positive effect on controlling NPS pollutants and soil erosion. Chinese scholars have tried a variety of protective measures, including reduced tillage and no tillage. Furthermore, there is great interest in China about the Membrane Controlled Release (MCR) technology used to control NPS 
emissions and the nitrification inhibitor technology used as a source control technique.

Process control techniques: The application of NPS process control techniques has received a great deal of attention in China in recent decades. These techniques include constructed wetlands, riparian vegetation buffers, multi-pond systems, soil and water conservation technologies, hybrid eco-agriculture (a rice-fish-azolla mode, a mulberry-silkworm-fish mode, and other modes with Chinese agroeconomic characteristics), and scientific irrigation methods (including seepage prevention, lining and border check irrigation technologies) [40]. In recent years, research about riparian vegetation buffers has included an extensive range of quantitative studies. By constructing a riparian vegetation buffer field experiment, the quantitative effects of buffers on runoff and the pollutant concentrations can be tested. Multi-pond systems in hilly regions in southern China play an important role in reducing surface runoff, sediment, and pollution. However, these techniques still only focus on a single 'point', considering little about integrity and systematization, and remain in the experimental stage, lacking large-scale application [41].

Terminal control techniques: The application of NPS terminal control techniques includes rural sewage treatment, standardization of livestock and poultry, breeding, aquatic plant purification, solid waste treatment (such as biogas digester construction, etc.), and agricultural waste recycling (such as returning straw to the field, etc.) [42]. However, due to wide scale and large amount of NPS pollution in China, relying solely on the end control techniques is not a long-term solution due to its large amount of cost.

\section{Integration techniques for controlling NPS pollution}

Integration of $3 \mathrm{~S}$ technique: The efficient management of NPS monitoring and control involves the capacity of GIS for comprehensive spatial analysis information management, the capacity of RS for monitoring spatial dynamics, and the high-precision positioning capability of GPS. There has been a great deal of research on $3 \mathrm{~S}$ application in China. Liu et al. [43] constructed an information system to simulate the relationship between land use/cover change and NPS pollution in the Yangtze River Basin using 35 techniques. This system helped to maintain the ecological balance and to encourage reasonable land management practices in that area. $\mathrm{Xu}$ et al. [44] extracted soil erosion environment factor information by using $3 \mathrm{~S}$ technology and put forward soil erosion control strategy in the three gorges reservoir area.

Integration of a Decision Support System (DSS): A DSS is a powerful tool that is used to select effective pollution control methods. The introduction of DSS helps managers to achieve multi-objective decision-making and global optimization when designing NPS control programs. At present, Chinese scholars use a DSS containing a "Three Components" structure (including a human-computer interaction system, a model management system and a database management system) to provide decision support for NPS pollution management. Li et al. [45] developed a non-point source pollution management decision support system based on hydrological models and Geographic Information System (GIS) in the Tongzhou district and Daxing district, in Beijing, China. Chen [2] constructed a non-point sources pollution decision support system (NPSDSS) based on a combination of the IMPULSE model, an NPS survey model, a GIS toolbox, and a screening model of pollution control practices. Then, they applied this system to assess the NPS pollution situation in the Dianchi Lake Basin and obtained satisfactory results. Zhang et al. [46] developed a model-based decision support system for supporting water quality management under hybrid uncertainties based on a hybrid uncertain programming (HFICP) model which can facilitate the decision making in planning agricultural activities for water quality management in agricultural systems.

\section{Integrated practices and a technology system for controlling NPS pollution}

Best Management Practices (BMPs): A series of independent practices constitute the BMPs, which are comprehensive practices that are integrated with structural practices and non-structural practices. Structural practices include terraces, hillside ditches, grass waterways, and others. Their primary impact is to reduce run-off through increased infiltration. Non-structural practices consist of cultural practices (conservation tillage, contour cropping, crop rotation, etc.) and management practices (integrated pest management, fertility and irrigation management, etc.). Various BMPs have already been introduced as a single technique for controlling NPS pollution. However, the adoption of the single BMP may not meet the water quality objectives; systematic BMPs will help control NPS pollution, which depends on the actual situation and the reduction target. There are two main optimization methods; one method is based on expert experience and identifies critical source areas [47,48], while the other is an optimization algorithm method [49,50]. But research about the optimal allocation of BMPs in China has only recently begun. Shen et al. [51] used the genetic algorithm for optimizing BMPs in the Yulin watershed in Southwestern China. Wang et al. [52] studied the environmental and economic benefits of several BMPs in the Miyun reservoir, in Beijing. Multiple attribute decision making based on information entropy was used to optimizing BMPs in the Dangjiangkou Reservoir basin [53]. Research about BMP optimization is still very limited in China, especially in the study of environmental and economic evaluation. Furthermore, most of the BMP measures are used for nitrogen, phosphorus, and sediment, but the measures of other types of pollutants such as pesticides and bacteria are limited. Overall, BMPs have been limited to in local areas in China, and further studies that extend BMP types and optimizations to the entire watersheds are needed in the near future.

Total Maximum Daily Load (TMDL): Methods to control the total amount of water pollutants are one of the most important ways to protect and improve water quality at a whole area scale. As the latest technology for controlling total loads, which is carried out comprehensively around the world, TMDL has attracted the attention of some Chinese researchers and administrators. Although TMDL studies in China have just begun in recent years, the rhythm of their development is quite rapid. Ding [54] applied a duration curve method, which is included in the TMDL program toolbox, to estimate the TP TMDL in the upper basin of the Daning River. He initially allocated the TP load to pollution sources by using a relevant TMDL formula and then ran a SWAT model to analyze the characteristics of the pollution load distribution over the whole watershed. Zhao et al. [55] applied a three-dimensional hydrodynamic and water quality model to reduce the watershed load through the total maximum daily load (TMDL) program in Lake Fuxian.

\section{Policies and pollution control measures}

China has already set up a series of measures and laws on non-point source pollution [56]. Take the Major Science and Technology Program for Water Pollution Control and Treatment, for example, 
which play an important role in controlling water pollution. This control measure obtained very good results in controlling source pollution, reducing pollution emissions, and researching key technological equipment. The control measures, which focus on the key rivers and lakes in China, are making progress, such as the pollution control of Taihu. Because this program involves gradually intensifying studies, it will make an important contribution to the future of Chinese pollution control.

\section{Recommendations for Future Studies}

According to the summary of this study, the research about China's agricultural non-point source pollution still in its infancy, but the researches in some aspects have made progress. Varieties of non-point source pollution models were widely used in Chinese; the model suitable for national condition was developed and management measures for agriculture non-point source pollution were widely used. Considering the current research situation and the problems that are occurring in China, future work on the development of agricultural NPS should focus on the following goals:

\section{NPS mechanism studies}

NPS pollution is a complicated and synthetic process that involves multiple processes related to hydrology, weather, environment, and ecological methodology. Therefore, there is an urgent need to study NPS pollution sources, contributions, transport mechanisms, and early-warning risk assessments based on the integration of different theories.

Current studies about NPS control in China concentrate on a smallscale area, whereas the spatiotemporal characteristics of NPS vary from one area to another. Therefore, we need to strengthen the largescale watershed research based on China's actual conditions.

Different types and distribution patterns of landscapes, precipitation, soil texture, and tillage practices affect nutrient losses and other NPS pollutants in different ways. The migration and transformation mechanisms of pollutants under the influence of multiple factors need to be studied further, to lay a solid foundation for NPS modeling improvements.

Much research has been carried out about the loss and transfer of nutrients and sediment, but there is less research about pesticides and bacteria, especially about the transformation and transport mechanisms of nitrogen, phosphorus, pesticides, and the sediment coupling effect; these issues need further research.

\section{NPS modeling studies}

Establish model database: The problem of insufficient data exists not only for foreign models but also for our models. Establishing a database that includes long-term monitoring data will provide basis for later research.

Model improvement and innovation: Considering the structural defects of NPS models, future studies should focus on improving existing model structures to better describe the NPS pollution taking into account China's actual conditions and to avoid introducing too many parameters; to construct flexible models for different situations despite limited data and a shortage of long-term monitoring information; and to develop distributed hydrological models for multiscale watersheds to describe the heterogeneity, nonlinear aspects, and complexity of spatial multiple-scale hydrological parameters.
Model uncertainty: Recently, major difficulties related to the uncertainty of NPS analysis technology have arisen in the process of quantifying uncertain factors and reducing uncertainty in model simulation. Future studies will focus on improving parameter calibration, optimizing of data acquisition solutions, and improving the uncertainty of analysis technology.

Model integrity: Future studies of NPS model integration should emphasize the following: the integration of multi-process models (to consider the process after NPS pollutants get into the ecosystem); $3 \mathrm{~S}$ technology (to increase the ability for data acquisition, visualize the simulation results, and increase the estimation accuracy); and large watershed management models. Therefore, integrating different processes and elements is one of the main trends in the gradual systematization of NPS models.

\section{NPS control technology and system studies}

Studies about the integration of different BMPs and optimal BMP allocations have just begun in China and need more research. Some NPS control technologies have become relatively mature but are not popular or widely applied. Therefore, expanding the use of existing technologies is imperative. Furthermore, implementation of the TMDL program is a developing trend in international water quality management. To expand the depth and extent of TMDL application, scholars should focus on studying NPS pollution models and management tools in depth, strengthening public participation, and quantitatively assessing the cost-effectiveness of program implementation.

Overall, many advanced control technologies, such as BMPs and TMDL, introduced and applied in China gradually; Chinese scholars developed an NPS management goal based on an approximate method of total amount control to watershed water quality control based on control unit. To develop future water quality management and control systems, Chinese researchers need to explore new theoretical approaches and integrated technology and management systems. Suggestions for future studies are as follows: to introduce landscape patterns and the ecological processes theory into NPS control studies; to establish ecological and technical regulations; to build a critical source areas identification method; to develop a watershed NPS pollution control optimization technology based on a decision support system; to determine the safety margin of in TMDL on the basis of an uncertainty analysis; to conduct an emissions trading study combined with zoning of water functions; and finally, to establish the watershed scale of an integrated NPS pollution control and management system based on all of the above technologies, which will not only provide a theoretical basis and technology paradigm for water pollution control but will also deepen and expand the watershed water environment system theory in China.

\section{Acknowledgements}

The study was supported by National Science Foundation for Innovative Research Group (No. 51121003), National Science Foundation for Distinguished Young Scholars (No. 51025933) and National Basic Research Program of China (973 Program, 2010CB429003). 


\section{References}

1. Ongley E D, Zhang XL, Yu T (2010) Current status of agricultural and rural non-point source pollution assessment in China. Environmental Pollution 158: 1159-1168

2. Chen JN (2009) Nonpoint source pollution control: case studies in Dianchi Lake catchments (in Chinese) China Environmental Science Press, Beijing.

3. Yang GS, Wang JD (2003) Economic development, water environment and water-related disasters in Taihu basin (in Chinese). Science Press, Beijing, China.

4. Sun B, Zhang LX, Yang LZ, Zhang FS, Norse D, et al. (2012) Agricultural Non-Point Source Pollution in China: Causes and Mitigation Measures. Academy of Sciences 41: 370-379.

5. Zhang SL, Zhuang JP (1998) Current situation and development tendency of researches of non-point source pollution in agriculture. Chinese Journal of Ecology 17: 51-55.

6. Shen ZY, Chen L, Xu L (2012) A Topography Analysis Incorporated Optimization Method for the Selection and Placement of Best Management Practices. Plos One 8: e54520.

7. Hou XY, Ying LL, Chang YY, Song SQ, Zhang Y (2013) Modeling of non-point source nitrogen pollution from 1979 to 2008 in Jiaodong Peninsula, China. Hydrological Processes 28: 3264-3275.

8. Li HE, Shen J (1996) Non-point source mathematical model (in Chinese). Northwestern Polytechnical University Press, Xian, China.

9. Liu QJ, Cai QG, Lv GA, Liu JG (2004) Study on soil erosion forecasting model with different spatial scales for loess region 7: 13-15.

10. Wu Y, He SM, Li XP (2008) The hydrodynamic mechanism of slope erosion under rainfall. Ecology and Environment (in Chinese) 17: 2440-2444.

11. Wu XL, Wang XM (2011) Spatial Influence of Geographical Factors on Soil Erosion in Fuyang County, China. Procedia Environmental Sciences 10: 2128-2133.

12. Liu GH, Liu JW, Zhu YH (2001) Land-unit based flow network model in small catchment with GIS support. Progress in Geography (in Chinese) 21: 139-145.

13. Peng T, Wang SJ (2012) Effects of land use, land cover and rainfall regimes on the surface runoff and soil loss on karst slopes in southwest China. Catena 90: 53-62.

14. Liu Y, Fu BJ, Lü YH, Wang Z, Gao GY (2012) Hydrological responses and soil erosion potential of abandoned cropland in the Loess Plateau, China. Geomorphology 138: 404-414.

15. Liu RM, Wang JW, Shi JH, Chen YX, Sun CC, et al. (2014) Runoff characteristics and nutrients loss mechanism from plain farmland under simulated rainfall conditions. Science of the Total Environment 468: 1069-1077.

16. Gan ZT, Ye J, Zhou Q, Zhou ZC, Shangguan ZP (2010) Effects of grass vegetations on the processes of soil erosion over slope lands in simulated rainfalls. Acta Ecologica Sinica (in Chinese) 30: 2387-2396.

17. Zhou L (2006) Research on transport and transformation law of agricultural non-point source pollution (in Chinese). MS thesis, Hohai University, Nanjing, China 42-56.

18. Huang DF, Wang G, Li WH, Qiu XX (2009) Effects of different fertilization modes on vegetable growth, fertilizer nitrogen utilization, and nitrogen loss from vegetable field. Chinese Journal of Applied Ecology (in Chinese) 20: 631-638.

19. Cui LT, Li ZW, Wang LX, Geng SG (2006) Study progress of migration and transformation on non-point phosphorus in river basin. Journal of Agro-Environment Science (in Chinese) 25: 353-355.

20. Maringanti C, Chaubey I, Arabi M, Engel B (2008) A multi-objective optimization tool for the selection and placement of BMPs for pesticide control. Hydrology and Earth System Sciences Discussions 5: 1821-1862.

21. Luo YZ, Zhang XY, Liu XM, Ficklin D, Zhang MH (2008) Dynamic modeling of organophosphate pesticide load in surface water in the northern San Joaquin Valley watershed of California. Environmental Pollution 156: 1171-1181.

22. Luo YZ, Zhang MH (2010) Spatially distributed pesticide exposure assessment in the Central Valley, California, USA. Environ Pollut 158: 1629-1637.

23. Li YZ, Shi YC, Li BG, Lu JW (1993) Monitoring and prognosis of regional water and salt. Geoderma 60: 213-233.

24. Zhang D, Zhang WC, Zhu L, Zhu QA (2005) Improvement and application of SWAT - a physically based, distributed hydrological model, Scientia Geographica Sinica (in Chinese) 4: 434-440.

25. Hao FH, Yang ST, Cheng HG, Bu QY, Zheng LF (2006) A method for estimation of non-point source pollution load in the large-scale basins of China. Acta Scientiae Circumstantiae 26: 375-383.

26. Shen H, Zhang WS, Peng H, Peng J (2011) Impact of non-point pollution of phosphorus on water quality: a case study of the middle and lower reaches of Hanjiang River. Engineering Journal of Wuhan University (in Chinese) 44: 26-31.

27. Li HE, Cai M (2003) Relationship between nonpoint source nutrient load and sediment and its application. Scientia Geographica Sinica (in Chinese) 23: 460-463.

28. Luo X, Shi ZH, Yin W, Chen J, Li L, et al. (2010) Effects of land use structure on nitrogen export in Hujiashan watershed of Danjiangkou reservoir area. Environmental Science 31: 58-62.

29. Ding XW, Shen ZY, Hong Q, Yang ZF, Wu X, et al. (2010) Development and test of the export coefficient model in the upper reach of the Yangtze River. Journal of Hydrology 383: 233-244.

30. Cai M, Niu WH, Li WY (2006) Study on Pollution Load Partition of River Basin. Yellow river (in Chinese) 28: 24-26.

31. Li H, Lei XY, Jin C (2010) Parameter estimation and uncertainty analysis of SWAT model in upper reaches of the Heihe river basin. Hydrological Progress 23: 2744-2753.

32. Shen ZY, Chen L, Liao Q, Liu RM, Huang Q (2013) A comprehensive study of the effect of GIS data on hydrology and non-point source pollution modeling. Agricultural Water Management 118: 93-102.

33. Zhang ZH, Zhao CG, Li T (2005) Research on Contaminant Transport and Transform in Soil, Underground Water and Clay. Soil Journal of Soil and Water Conservation 19: 176-180.

34. Yang J, Reichert P, Abbaspour KC, Xia J, Yang H (2008) Comparing uncertainty analysis techniques for a SWAT application to the Chaohe basin in China. Journal of Hydrology 358: 1-23.

35. Cao WZ, Hong HS, Zhang YZ, Ding YH, Yue SP (2002) Testing AGNPS for water quality modeling in agricultural catchment in southeast of China. ACTA Scientiae Cireumstantiae 22: 537-540.

36. Li S, Liu L (2010) Evaluation of Ann AGNPS model for simulation water and sediment yield in the Lianshui river watershed. Chinese Journal of Environmental Science 31: 49-57.

37. Xue YF, Wang XY, Qin FL, Ou Y (2008) SWAT-based simulation on non-point source pollution in the northern watershed of Miyun reservoir. Journal of Agro-Environment Science 27: 1098-1105.

38. Zhang SL, Zhuang JP (2003) Study on distributed model of non-point sources pollution in agriculture on watershed scale. Journal of Arid Land Resources and Environment 17: 76-80.

39. Guo HP, Zhu JY, Yang YS (2008) Research status and development of technologies for controlling the agricultural non-point source pollution. Transactions of the CSAE (in Chinese) 24: 290-295.

40. Wu M, Tang XQ, Li QY, Yang WJ, Jin F, et al. (2013) Review of Ecological Engineering Solutions for Rural Non-Point Source. Water Pollution Control in Hubei Province, China. Water Air Soil Pollution 224: 1561-1579.

41. Song D, Cheng JM, Li Y, Jing LX, Zhang L (2010) The research of agricultural non-point source pollution. Environmental Science and Management (in Chinese) 35: 39-42.

42. Liu ZJ, Lu JH, Fang H, Zhang YA (2009) Types, characteristics, sources of non-point source pollution and its control technology. Anhui Agriculture and Science Bulletin (in Chinese) 15: 98-101 
Citation: Shen Z, Baia J, Liaoa Q, Chena L (2014) An Overview of China's Agricultural Non-point Source Issues and the Development of Related Research. Hydrol Current Res 5: 178. doi:10.4172/2157-7587.1000178

Page 7 of 7

43. Liu RM, Yang ZF, Shen ZY, Wu X (2006) Relationship and simulation information system of land use/cover change and non-point source pollution in Yangze river basin. Resources and Environment in the Yangze Basin (in Chinese) 15: 372-377.

44. Xu XH, Xu XF, Lei S, Fu SS, Wu GW (2011) Soil Erosion Environmental Analysis of the Three Gorges Reservoir Area Based on the“3S"Technology. Procedia Environmental Sciences 10: 2218-2225.

45. Li M, Guo P, Liu X, Huang GH, Huo ZL (2013) A decision-support system for cropland irrigation water management and agricultural nonpoint sources pollution control. Desalination and Water Treatment 52: 5106-5117.

46. Zhang XD, Huang GH, Nie XH, Lin QG (2011) Model-based decision support system for water quality management under hybrid uncertainty. Expert Systems with Applications 38: 2809-2816.

47. Gburek WJ, Sharpley AN, Heathwaite L, Folmar GJ (2000) Phosphorus management at the watershed scale: A modification of the phosphorus index. Journal of Environmental Quality 29: 130-144.

48. Strauss P, Leone A, Ripa MN, Turpin N, Lescot JM, et al. (2007) Using critical source areas for targeting cost-effective best management practices to mitigate phosphorus and sediment transfer at the watershed scale. Soil Use and Management 23: 144-153.

49. Maringanti C, Chaubey I, Arabi M, Engel B (2011) Application of a multi-objective optimization method to provide least cost alternatives for NPS pollution control. Environmental Management 48: 448-461.
50. Rabotyagov S, Campbell T, Jha M, Gassman PW, Arnold J, et al. (2010) Least-cost control of agricultural nutrient contributions to the Gulf of Mexico hypoxic zone. Ecological Applications 20: 1542-1555.

51. Shen ZY, Liao Q, Hong Q, Gong YW (2012) An overview of research on agricultural non-point sources pollution modelling in China. Separation and Purification Technology 84: 104-111.

52. Wang XY, Zhang YF, Ou Y, Zhang YM (2009) Predicting effectiveness of best management practices for control of nonpoint source pollution: a case of Taishitun Town, Miyun County, Beijing. Acta Scientiae Circumstantiae 29: 2440-2450.

53. Wang X, Hao FH, Zhang X (2013) Optimization of best management practices for non-point source pollution in Danjiangkou Reservoir Basin. China Environmental Science 33: 1335-1343.

54. Ding JT (2009) Research on estimation and allocation of total phosphorus TMDL in Wuxi Reach, Daning River. MS thesis, Beijing University of Chemical Technology, Beijing, China.

55. Zhao L, Zhang XL, Liu Y, He B, Zhu X, et al. (2012) Three-dimensional hydrodynamic and water quality model for TMDL development of Lake Fuxian, China. Journal of Environmental Sciences 24: 1355-1363.

56. Wang CM, Lin ZL (2010) Environmental Policies in China over the Past 10 Years: Progress, Problems and Prospects. Procedia Environmental Sciences 2: 1701-1712. 